\title{
Evaluation of the risk of musculoskeletal disorders using Rapid Entire Body Assessment among hairdressers in Khorramabad, Iran, in 2014
}

\author{
Mahdavi S, $\mathrm{MSc}^{1}$, Mahdavi MR, $\mathrm{BSc}^{2}$, Safari M, $\mathrm{MSc}^{3}$, Rashidi R, $\mathrm{PhD}^{4}$, Dehghani $\mathrm{T}, \mathrm{BSc}^{5}$, Kosari \\ $\mathrm{M}, \mathrm{BSc}^{6}$ \\ 1-Faculty Member, Dept. of Occupational Health Engineering, School of Health, Lorestan University of Medical \\ Sciences, Khorramabad, Iran. 2- BSc Student, Dept. of Biomechanics, School of Physical Education and Sport Sciences, \\ South Tehran Branch, Islamic Azad University, Tehran, Iran. 3- Faculty Member, Dept. of Epidemiology, School of \\ Health, Lorestan University of Medical Sciences, Khorramabad, Iran. 4- Assistant Prof., Dept. of Occupational Health \\ Engineering, School of Health, Lorestan University of Medical Sciences, Khorramabad, Iran. 5- MSc Student, Dept. of \\ Occupational Health Engineering, School of Health, Lorestan University of Medical Sciences, Khorramabad, Iran. 6- MSc \\ Student, Dept. of Occupational Health Engineering, School of Health, Lorestan University of Medical Sciences, \\ Khorramabad, Iran.
}

Background: Work-related musculoskeletal disorders (WRMSDs) are considered a major factor in health problems, human injuries, and loss of work time. The aim of the present study was to assess the risk of musculoskeletal disorder (MSD) and evaluate the prevalence of MSD among female hairdressers.

Materials and Methods: In this descriptive analytical study, the risk of MSDs was evaluated in 172 female hairdressers using the Rapid Entire Body Assessment (REBA) method. Moreover, the prevalence of WRMSDs was investigated using a Nordic questionnaire. All obtained data was analyzed by means of SPSS software, and the logistic regression model.

Results: The results showed that $58.7 \%$ of the hairdressers experienced pain in their lower back, $52.3 \%$ in their neck, $41.3 \%$ in their knees, and $20.3 \%$ in their ankle. The results of this study showed a significant correlation between BMI and MSDs in the elbow, hip, and thigh. The results of REBA indicate that about $46 \%$ of the 1032 postures were classified as high risk and about $14.9 \%$ as very high risk. In addition, the results of this study showed a significant correlation between REBA score and MSDs in the neck, wrist, hip, and thigh.

Conclusions: With regard to the high prevalence of symptoms in the waist, neck, and wrist, it can be concluded that prolonged standing, uncomfortable working postures, strenuous movements, excessive shoulder flexion and shoulder abduction, trunk flexion and forceful exertion, and repetitive motion are considered important risk factors for MSDs.

Keywords: Risk, Body, Assessment, Musculoskeletal Disorders.

\section{Introduction}

Work-related musculoskeletal disorders (WRMSDs) are one of the major occupational health problems in many countries and musculoskeletal disorders (MSDs) are common among hairdressers $(1,2)$.

Hairdressers are exposed to various hazards in the workplace such as awkward posture, load on the muscles, nerves, tendons, and joints, prolonged standing, and physical and chemical agents (3). Leino stated that hairdressers are exposed to chemical and ergonomic agents and work-relateddisorders, although the risk of WRMSDs was the greatest among them (4). According to the results of a National Health Interview Survey In 2002 by Guo, of the top 15 major occupations, female hairdressers were the third most at risk for work-related lower back pain (5). Pain and discomfort in the neck, wrist/hand, and lower back region were

\footnotetext{
* Corresponding author: Sakineh Mahdavi, Dept. of Occupational Health Engineering, School of Health, Lorestan University of Medical Sciences, Khorramabad, Iran.

Email: smahdavi125@yahoo.com
} 
commonly reported by Greek hairdressers. These were related to prolonged sitting, upper arms elevation, inappropriate body postures, and use of vibrating tools (6). According to another research, manual material handling, prolonged standing, awkward working postures, strenuous movements, excessive shoulder flexion and abduction, trunk flexion and forceful exertion, and repetitive motion are considered common risk factors for MSDs (7). In addition, working with upper arms above shoulder height is considered a major risk factor for neck and shoulder pain $(8,9)$. Moreover, most studies stated that the static activity of the muscles of the neck and shoulder and static loadings restrict blood flow to the muscles and tendons, and mechanical stress on the shoulder muscles or tendons could possibly be due to pathophysiological mechanisms (10).

Work is an important and integral segment of human life, but the development of technology has caused an increase in occupational diseases and WRMSDs are the most common among them $(11,12)$. In this regard, MSDs among hairdressers can be mentioned. A study assessing the risk factors of WMSDs for hairdressers stated that $91.7 \%$ of hairdressers reported shoulder pain as the most frequent problem followed by pain in the lower back $(83.3 \%)$ and in the neck region $(75 \%)(13)$.

Furthermore, other studies stated that inappropriate posture during work, repetitive movements, improper and long standing, use of inappropriate tools, working with the elbow above shoulder height, excessive shoulder flexion and shoulder abduction, and pronation and supination are considered important risk factors for WRMSDs among hairdressers (14, 15). These disorders can be prevented by the use of ergonomics such as risk assessment methods, job analysis methods, evaluation of work situations, and improvement of job situations $(14,15)$.

Therefore, the aim of this study was to assess the risk of MSD by using Rapid Entire Body Assessment (REBA) method and evaluate the prevalence of MSD among female hairdressers by using a Nordic Questionnaire.

\section{Materials and Methods}

This descriptive analysis study was performed in 2014. First, the list of all the hairdressers working in Khorramabad, Iran, was obtained through a trade association. The number of female hairdressers in Khorramabad was 300. From among them, 172 subjects were selected through census sampling method according to the following equation:

$$
\mathrm{n}=\frac{\mathrm{Nz}^{2} \mathrm{pq}}{\mathrm{d}^{2}(\mathrm{~N}-1)+\mathrm{Z}^{2} \mathrm{pq}}=172
$$

In this equation, $\mathrm{p}=0.5, \mathrm{q}=0.5, \mathrm{z}=2, \mathrm{~d}=$ 0.05 , and $\mathrm{N}=300$. All subjects possessed professional certificates. The MSDs of these 172 female hairdressers were evaluated. All tasks were observed by a trained occupational health and safety practitioner. In first step, the owner of each hairdressing salon was contacted to obtain permission to interview the hairdressers. In the second step, a meeting was held with the hairdressers to invite them to take part in the study and explain the objectives of the study. Data were collected using a Nordic Questionnaire for Musculoskeletal Symptoms of Pain or Discomfort.

The validity and reliability of the questionnaire have been determined in various studies (16-18). After the end of data collection, the prevalence of WRMDs for neck, shoulder, upper back, lower back, elbow/forearm, hand/wrist, and fingers were calculated. Then, ergonomic analyses of the work of the hairdressers were carried out. Next, the risk of MSDs was evaluated using the REBA method. The REBA is a posturebased analysis technique used for the evaluation of the risk of MSDs in various tasks, in particular for assessment of working postures in health care and other services in the work place $(19,20)$. 
Table 1: Rapid Entire Body Assessment (REBA) scores and indications

\begin{tabular}{cccc}
\hline Score & Risk level & Action level & Actions \\
\hline 1 & None risk & 0 & Not necessary \\
\hline 2 to 3 & Lower risk & 1 & Can be necessary \\
\hline 4 to 7 & Medium risk & 2 & It is necessary \\
\hline 8 to 10 & High risk & 3 & $\begin{array}{c}\text { It is necessary to } \\
\text { be done fast }\end{array}$ \\
\hline 11 to 15 & Very high risk & 4 & It is urgent \\
\hline
\end{tabular}

This ergonomic method is a systematic tool which is used to evaluate whole body postural WRMSDs and risks associated with occupational tasks. In this method, a single page worksheet is used to evaluate required or selected body postures, forceful exertions, type of movement, muscle activity (static/dynamic), repetition, and coupling. The REBA worksheet is divided into 2 body segment sections labeled A and B. Section A covers the neck, trunk, and leg. Section B covers the arm and wrist. Postures of hairdressers body regions are observed and postural scores increase with regarded to other items such as forceful exertions, type of movement, muscle activity (static/dynamic), repetition, and coupling. The scores are summed up to give one score for each posture (21). The obtained scores are compared in table 1. All data obtained was analyzed by means of SPSS software (version 16, SPSS Inc., Chicago, IL, USA) and logistic regression model.

Table 2: Demographics of hairdressers $(n=172)$

\begin{tabular}{ccccc}
\hline Index & $\mathrm{N}$ & $\mathrm{SD} \pm$ Mean & Min & Max \\
\hline Age (year) & 172 & $7.99 \pm 32.36$ & 18 & 68 \\
\hline Weight $(\mathrm{kg})$ & 172 & $1.08 \pm 65.73$ & 41.00 & 112.00 \\
\hline Height $(\mathrm{m})$ & 172 & $0.63 \pm 1.63$ & 1.39 & 1.78 \\
\hline
\end{tabular}

\section{Results}

In the present study, 172 female hairdressers participated. They were on average aged 32.36 years. Table 2 shows the mean and standard deviations of age, weight, and height. The prevalence of WRMDs for neck, shoulder, back, elbow/forearm, and hand/wrist is presented in table 3 .

Table 3: Prevalence of work-related musculoskeletal disorders (WRMSDs) for neck, shoulder, back, elbow/forearm, and hand/ wrist in the hairdressers $(n=172)$

\begin{tabular}{lccc}
\hline \multirow{2}{*}{ Limb } & Region & \multicolumn{2}{c}{ Musculoskeletal disorders } \\
\cline { 2 - 4 } & & $\mathbf{N}$ & $(\%)$ \\
\hline Neck & - & 90 & 52.3 \\
\cline { 2 - 4 } Shoulder & right & 32 & 18.6 \\
\cline { 2 - 4 } & left & 18 & 10.5 \\
\cline { 2 - 4 } Elbow & both & 35 & 20.3 \\
\cline { 2 - 4 } & right & 12 & 7 \\
\cline { 2 - 4 } & left & 5 & 2.9 \\
\hline \multirow{2}{*}{ Wrist and hand } & both & 7 & 4.1 \\
& right & 49 & 28.5 \\
\cline { 2 - 4 } & left & 9 & 15.1 \\
\hline Upper back & both & 26 & 39.5 \\
\hline Lower back & - & 68 & 58.7 \\
\hline Hip and thigh & - & 101 & 18 \\
\hline Knee & - & 31 & 20.3 \\
\hline Leg & - & 35 &
\end{tabular}


Table 4: Frequency distribution of risk in the each of the postures

\begin{tabular}{lcccccccc}
\hline Task & $\begin{array}{l}\text { Low level risk } \\
\text { (action level 1) }\end{array}$ & \multicolumn{2}{c}{$\begin{array}{c}\text { Moderate level risk } \\
\text { (action level 2) }\end{array}$} & $\begin{array}{c}\text { High level risk } \\
\text { (action level 3) }\end{array}$ & $\begin{array}{c}\text { Very High level risk } \\
\text { (action level 4) }\end{array}$ \\
\cline { 2 - 8 } & Frequency & Percentage & Frequency & Percentage & Frequency & Percentage & Frequency & Percentage \\
\hline $\begin{array}{l}\text { Trimming } \\
\text { eyebrows }\end{array}$ & 8 & 4.6 & 79 & 45.7 & 82 & 47.4 & 3 & 1.7 \\
\hline $\begin{array}{l}\text { Trimming } \\
\text { face }\end{array}$ & 9 & 5.2 & 57 & 33.1 & 90 & 52.3 & 16 & 9.3 \\
\hline Makeup & 7 & 4.1 & 74 & 43 & 83 & 48.3 & 8 & 4.4 \\
\hline Hair-cutting & 18 & 10.5 & 44 & 25.6 & 77 & 44.8 & 33 & 19.2 \\
\hline Hairdressing & 4 & 2.3 & 49 & 28.3 & 64 & 37 & 55 & 31.8 \\
\hline Hair-coloring & 7 & 4.1 & 52 & 30.2 & 79 & 45.9 & 34 \\
\hline
\end{tabular}

After the end of the initial survey and interview with hairdressers, ergonomic analyses of the work of the hairdressers in 6 important tasks were carried out according to services offered (such as trimming, makeup, hair-cutting, hair-coloring, and hair-perming). The risk of MSDs by using RULA is presented in table 4 in the each of 6 tasks. In total, 1032 postures were evaluated. The risks of MSDs, using RULA, are presented in table 5 in the 1032 postures. According to table 5, most of the studied postures are classified as medium $(34.4 \%)$ and high risk postures $(46 \%)$.

Table 5: Percentage of risk of Rapid Entire Body Assessment (REBA) outputs $(n=$ 1032 postures)

\begin{tabular}{lccc}
\hline Risk level & Action Level & Number of task & Percentage of task \\
\hline No risk & 0 & 0 & 0 \\
\hline Low risk & 1 & 53 & 5.1 \\
\hline Medium risk & 2 & 355 & 34.4 \\
\hline High risk & 3 & 475 & 46 \\
\hline Very high risk & 4 & 149 & 14.9 \\
\hline
\end{tabular}

The results of logistic back ward logistic regression analyses on risk factors of musculoskeletal disorder for the body regions such as wrists, forearms, elbows, shoulders, neck, trunk, back, legs, and knees are presented in table 6. Table 7 shows the results of logistic back ward logistic regression analyses on the musculoskeletal disorder for different regions of the body and REBA scores in each task. 
Table 6: Analysis of statistical value between musculoskeletal disorder (MSD) and age, weight, height, and BMI

\begin{tabular}{|c|c|c|c|c|c|c|c|c|c|c|}
\hline \multirow[b]{2}{*}{$\begin{array}{l}\text { Measured } \\
\text { index }\end{array}$} & \multirow[b]{2}{*}{$\begin{array}{l}\text { Statistical } \\
\text { value }\end{array}$} & \multicolumn{9}{|c|}{ Musculoskeletal disorders in different regions of the body } \\
\hline & & Neck & Shoulder & Elbow & $\begin{array}{l}\text { wrist } \\
\text { and } \\
\text { hand }\end{array}$ & $\begin{array}{l}\text { Upper } \\
\text { back }\end{array}$ & $\begin{array}{l}\text { Lower } \\
\text { back }\end{array}$ & $\begin{array}{l}\text { Hip and } \\
\text { thigh }\end{array}$ & Knee & Leg \\
\hline \multirow{2}{*}{ Age (year) } & P-value & 0.01 & 0.025 & 0.358 & 0.095 & 0.388 & 0.117 & 0.036 & 0.02 & 0.882 \\
\hline & $\mathbf{N}$ & 172 & 172 & 172 & 172 & 172 & 172 & 172 & 172 & 172 \\
\hline \multirow{2}{*}{ Weight (kg) } & P-value & 0.431 & 0.757 & 0.058 & 0.203 & 0.148 & 0.202 & 0.030 & 0.129 & 0.694 \\
\hline & $\mathbf{N}$ & 172 & 172 & 172 & 172 & 172 & 172 & 172 & 172 & 172 \\
\hline \multirow{2}{*}{ Height (m) } & P-value & 0.698 & 0.763 & 0.087 & 0.196 & 0.130 & 0.138 & 0.034 & 0.145 & 0.644 \\
\hline & $\mathbf{N}$ & 172 & 172 & 172 & 172 & 172 & 172 & 172 & 172 & 172 \\
\hline \multirow{2}{*}{ BMI } & P-value & 0.368 & 0.826 & 0.053 & 0.213 & 0.149 & 0.232 & 0.039 & 0.109 & 0.695 \\
\hline & $\mathbf{N}$ & 172 & 172 & 172 & 172 & 172 & 172 & 172 & 172 & 172 \\
\hline
\end{tabular}

Table 7: Analysis of statistical value between musculoskeletal disorder (MSD) in the regions of body and Rapid Entire Body Assessment (REBA) Scores in each task

\begin{tabular}{|c|c|c|c|c|c|c|c|c|c|c|}
\hline \multirow{2}{*}{ Measured index } & \multirow[b]{2}{*}{$\begin{array}{l}\text { statistical } \\
\text { value }\end{array}$} & \multicolumn{9}{|c|}{ Musculoskeletal disorders in different region of the body } \\
\hline & & Neck & Shoulder & Elbow & $\begin{array}{c}\text { wrist } \\
\text { and } \\
\text { hand }\end{array}$ & $\begin{array}{c}\text { Upper } \\
\text { back }\end{array}$ & $\begin{array}{c}\text { Lower } \\
\text { back }\end{array}$ & $\begin{array}{l}\text { Hip and } \\
\text { thigh }\end{array}$ & Knee & Leg \\
\hline \multirow{3}{*}{$\begin{array}{l}\text { REBA score } \\
\text { (Trimming } \\
\text { eyebrows) }\end{array}$} & OR & 1.238 & 1.028 & 1.234 & 1.329 & 1.081 & 1.114 & 1.086 & 1.107 & 1.378 \\
\hline & P-value & 0.021 & 0.820 & 0.265 & 0.025 & 0.542 & 0.379 & 0.651 & 0.433 & 0.001 \\
\hline & $\mathbf{N}$ & 172 & 172 & 172 & 172 & 172 & 172 & 172 & 172 & 172 \\
\hline \multirow{3}{*}{$\begin{array}{c}\text { REBA score } \\
\text { (Trimming face) }\end{array}$} & OR & 0.910 & 0.927 & 0.792 & 0.811 & 0.939 & 0.963 & 0.963 & 0.956 & 1.288 \\
\hline & P-value & 0.469 & 0.542 & 0.224 & 0.102 & 0.626 & 0.765 & 0.828 & 0.729 & 0.144 \\
\hline & $\mathbf{N}$ & 172 & 172 & 172 & 172 & 172 & 172 & 172 & 172 & 172 \\
\hline \multirow{3}{*}{$\begin{array}{l}\text { REBA score } \\
\text { (Make up) }\end{array}$} & OR & 1.026 & 1.177 & 1.043 & 0.833 & 1.215 & 0.942 & 1.144 & 1.052 & 0.804 \\
\hline & $P$-value & 1.837 & 0.019 & 0.832 & 0.152 & 0.007 & 0.628 & 0.446 & 0.698 & 0.259 \\
\hline & $\mathbf{N}$ & 172 & 172 & 172 & 172 & 172 & 172 & 172 & 172 & 172 \\
\hline \multirow{3}{*}{$\begin{array}{c}\text { REBA score } \\
\text { (Hair-cutting) }\end{array}$} & OR & 1.299 & 1.090 & 1.443 & 1.208 & 1.217 & 1.099 & 0.806 & 1.084 & 1.073 \\
\hline & P-value & 0.041 & 0.539 & 0.098 & 0.051 & 0.176 & 0.085 & 0.261 & 0.586 & 0.703 \\
\hline & $\mathbf{N}$ & 172 & 172 & 172 & 172 & 172 & 172 & 172 & 172 & 172 \\
\hline \multirow{3}{*}{$\begin{array}{c}\text { REBA score } \\
\text { (Hairdressing) }\end{array}$} & OR & 1.040 & 1.012 & 0.825 & 0.988 & 1.070 & 0.979 & 1.357 & 1.152 & 1.078 \\
\hline & $P$-value & 0.795 & 0.935 & 0.377 & 0.935 & 0.655 & 0.886 & 0.004 & 0.079 & 0.700 \\
\hline & $\mathbf{N}$ & 172 & 172 & 172 & 172 & 172 & 172 & 172 & 172 & 172 \\
\hline \multirow{3}{*}{$\begin{array}{c}\text { REBA score } \\
\text { (Hair-coloring) }\end{array}$} & OR & 0.709 & 0.892 & 0.923 & 0.944 & 0.834 & 0.968 & 0.948 & 0.988 & 0.815 \\
\hline & $P$-value & 0.009 & 0.403 & 0.690 & 0.676 & 0.207 & 0.811 & 0.790 & 0.935 & 0.258 \\
\hline & $\mathbf{N}$ & 172 & 172 & 172 & 172 & 172 & 172 & 172 & 172 & 172 \\
\hline
\end{tabular}




\section{Discussion}

In the present study, $58.7 \%$ of the hairdressers experienced pain in their lower back, $52.3 \%$ in their neck, $41.3 \%$ in their knees, $20.3 \%$ in their ankle, $28.5 \%$ in their dominant right wrist and hand, 5.2\% in their left wrist and hand, and $15.1 \%$ in both their wrists and hands. About $20.3 \%$ of hairdressers experienced pain in both their shoulders. The results of a similar survey conducted by Mussi revealed that most of the discomfort is experienced in the shoulders (49\%), neck (47\%), and back (39\%) (22).

According to the research by Chuang, $94.4 \%$ of hairdressers stated that they felt the greatest discomfort in their shoulders, followed by the lower back and neck (23).

Kang evaluated the prevalence of work-related symptoms among hairdressers (24). The exposed group comprised 184 hair salon employees in 6 districts of Pusan city, and the non-exposed group comprised 119 individuals living in the same areas. They reported that the prevalence of musculoskeletal symptoms among Korean hairdressers was $59.9 \%$ in the neck, $76.6 \%$ in shoulders, $41.2 \%$ upper back, $72.2 \%$ lower back, $31.3 \%$ arm and elbow, $44.2 \%$ wrist, $35.0 \%$ finger, and $71.1 \%$ in legs (24).

According to the study by Hokm Abadi, the prevalence of disorders in different parts of the body was as follows: $8 \%$ in the wrist, $20 \%$ the neck, $36 \%$ shoulders, $46 \%$ back, and $84 \%$ in the legs (25). In a similar study by Miri, the prevalence of WRMSD in different regions of body was as follows: $21 \%$ in the neck, $31 \%$ shoulders, $6 \%$ wrist, $54 \%$ back, and $69 \%$ in the legs (26).

On the other hand, in the present study, the results of REBA indicate that a high percentage of hairdressers are at high to very high risk of MSDs. Only about $46 \%$ of the 1032 postures were classified as the action category/level 3 (high risk) and about 14.9\% of the postures were classified as action level 4 (very high risk) which requires immediate corrective change in postures, but about $34.4 \%$ of the postures were classified as action level 2 (medium risk) by REBA. Results of a similar study conducted by Hokm Abadi showed that about $56 \%$ of the postures related to the right side of the body were classified as medium level and about $30 \%$ as high level, but about $76 \%$ of the postures related to the left side of the body were classified as medium level and about $16 \%$ as high level using REBA (25). Furthermore, the results of the study by Miri showed that about $42 \%$ of the postures related to the right side of the body were classified as medium level and about $38 \%$ as high level, but about $46 \%$ of the postures related to the left side of the body were classified as medium level and about $40 \%$ as high level using REBA (26). Nevertheless, in the research by Frvarsh, about $27.6 \%$ of the postures were classified as action level 2-3 (medium risk-high risk) using REBA (27).

The results of this study showed a significant correlation between BMI and MSDs in the elbow, hip, and thigh. The finding of this study revealed a significant correlation between age and MSDs in the knee, shoulder, and neck.

Moreover, the results of this study showed a significant correlation between REBA score and MSDs in the neck, wrist, hip, and thigh.

The study by Miri demonstrated a significant correlation between duration of work and MSDs in the leg (26). It also showed a significant correlation between REBA score and MSDs in the legs and wrist (26).

According to the research by Best, $70 \%$ of hairdressers suffered from MSDs (28). In addition, uncomfortable working posture and standing for a long period of time are the greatest causes of MRMSDs in hairdressers (28).

Uncomfortable working posture, standing for a long period of time, unsuitable tools and equipment such as unsuitable chairs, clipper, razors, blow-dryer, and scissors, and working with a shoulder or shoulders raised, bending forward or sideways, bending the head forward or sideways, and twisting the neck can led to high risk score in hairdressers. 


\section{Conclusions}

With regard to the results obtained in this study, it is concluded that the hairdressers are at high risk of MSDs. Furthermore, in order to reduce WRMSDs, risk level should be reduced though design and using of ergonomic and appropriate tools and equipment.

\section{Acknowledgment}

This study was supported by the Nutritional Health Research Center of Lorestan University of Medical Sciences, Khorramabad, Iran, and the authors would like to acknowledge the support from this research center.

Conflict of interest: Non declared

\section{References:}

1- Riihimaki H, Viikari-Juntura E. Musculoskeletal system. In: Stellman JE, editors. Encyclopedia of Occupational Health and Safety. $4^{\text {th }}$ ed. Geneva: International Labour Office 1998; 6:1-35.

2- Pinar T, Cakmak ZA, Saygun M, Akdur R, Ulu N, Keles I, Saylam HS. Symptoms of musculoskeletal disorders among ammunition factory workers in Turkey. Arch Environ Occup Health 2013; 68(1):13-21.

3- Mandiracioglu A, Kose S, Gozaydin A, Turken M, Kuzucu L. Occupational health risks of barbers and coiffeurs in Izmir. Indian J Occup Environ Med 2009; 13(2):92-6.

4- Leino T, Kahkonen E, Saarinen L, HenriksEckerman ML, Paakkulainen H. Working conditions and health in hairdressing salons. App Occup Environ Hyg 1999; 14(1):26-33.

5- Guo HR. Working hours spent on repeated activities and prevalence of back pain. Occup Environ Med 2002; 59(10):680-8.

6- Tsigonia A, Tanagra D, Linos A, Merekoulias G, Alexopoulos EC. Musculoskeletal disorders among cosmetologists. Int $\mathrm{J}$ Environ Res Public Health 2009; 6(12):2967-79.

7- Borg G. Psychophysical scaling with applications in physical work and the perception of exertion. Scand J Work Environ Health 1990; 16(1):55-8.

8- Hamberg-van Reenen HH, Ariëns GA, Blatter BM, Van Mechelen W, Bongers PM. A systematic review of the relation between physical capacity and future low back and neck/shoulder pain. pain 2007; 130(1-2):93107.

9- Ariëns G, Bongers P, Douwes M, Miedema M, Hoogendoorn W, Van der Wal G, et. al. Are neck flexion, neck rotation, and sitting at work risk factors for neck pain? Results of a prospective cohort study. J Occup Environ Med 2001; 58(3):200-7.

10- Sjøgaard G, Lundberg U, Kadefors R. The role of muscle activity and mental load in the development of pain and degenerative processes at the muscle cell level during computer work. Eur J Appl Physiol 2000; 83(2-3):99-105.

11- Chobineh AR. Human factors in industry and manufactory (ergonomic). Shiraz, Iran: Rahbord 1996.

12- Levy BS, Wegman DH, Baron SL, Sokas RK. Occupational and environmental health: recognizing and preventing disease and injury. $6^{\text {th }}$ edition. Philadelphia: Lippincott Williams \&Wilkins 2006; 488-516.

13- Fang HL, Chen RCC, Fang HP, Xu De Q. An ergonomic approach to an investigation into the risk factors leading to work related musculoskeletal disorders for Taiwanese hairdressers Mont fort University, UK Styling and Cosmetology Departmant, Transworld Institute of Technology, Taiwan 2007; 30:1-10.

14- Caren M .Ergonomomics-A BUZZ word. The perventive Angle 2002; 1(1):1-5.

15- Malone RE. Ergonomomics, policy, and the ED nurse. J Emerg Nurs 2000; 26(5):514-5.

16- Nasl-Saraji J, Fahol M, Golbabaei F, Lahmi M, Alimohammadi I. Assessment and evaluation of posture by RULA in an electronics and electricity manufactory in 2002. Iran Occupational Health Journal 2007; 4(3-4):1017.

17- Ghamari F, Mohamadbeigi A, Khodayari M. Work station revision by ergonomic posture analyzing of arak bakery workers. Journal of Zanjan University of Medical Sciences 2010; 18(70):81-90.

18- Habibi E, Poorabdian S, Ahmadinejad P, Hassanzadeh A. Ergonomic risk assessment by REBA method. Iran Occupational Health Journal 2007; 4(3-4):35-43.

19- Hignett S, McAtamney L. Rapid entire body assessment (REBA). Appl Ergon 2000; 31(2):201-5.

20- Winkle J, Westgaard RH. A model for solving work related musculoskeletal problems in a profitable way. Appl Ergon 1996; 27(2):71-7.

21- Motamedzade M, Ashuri MR, Golmohammadi R, Mahjub H. Comparison of ergonomic risk assessment outputs from rapid entire body assessment and quick exposure check in an engine oil company. J Res Health Sci 2011; 11(1):26-32.

22- Mussi G, Gouveia N. Prevalence of workrelated musculoskeletal disorders in Brazilian hairdressers. Occup Med 2008; 58(5):367-9.

23- Chuang W. A research on the Musculoskeletal Disorders of Hairdressers in Beauty Salons. Journal of Cheng-Shiu University Taiwan 2005; 18: 65-70.

24- Chen HC, Chang CM, Liu YP, Chen CY. Ergonomic risk factors for the wrists of hairdressers. Appl Ergon 2010; 41(1):98-105.

25- Hokmabadi RA, Esmailzadeh Kavaki M, Mehdinia M. Hairdressers by reba (Rapid 
ergonomic postures of evaluation of entire body assessment. Journal of North Khorasan University of Medical Science 2012; 3(4):4954.

26- Miri MR, Hosseini MH, Sharifzadeh GR. Evaluation of ergonomic postures of hairdressers by REBA in Birjand. Quarterly of the Horizon Medical Sciences 2008; 14(2):3944.

27- Foruresh E, Mazlomi A, Habibi-Mohraz M,
Taghavi-Shahri SM, Suri Sh, Moharrami S. Ergonomic evaluation of body postures and effective risk factors contributing musculoskeletal disorder in barbers in SARDASHT. Journal of Health and safety at work $2012 ; 1(2): 45-50$.

28- Best M, French GM, Cianter J. Work- related musculoskeletal disorders in hairdressers. Journal of occupational Health and Safety 2002; 1(18):66-7. 